\title{
THE PHOSPHOLIPIDS AND PHOSPHOLIPID-BOUND FATTY ACIDS AND ALDEHYDES OF DOG AND FOWL SPERMATOZOA
}

\author{
ANNABELlE DARIN-BENNETT, A. POULOS* AND I. G. WHITE \\ Department of Veterinary Physiology, \\ University of Sydney, N.S.W. 2006, Australia
}

(Received 3rd May 1974)

Recent work has established the composition of phospholipids and phospholipidbound fatty acid esters and aldehydes in ram, bull, boar, human and rabbit spermatozoa (Scott, Voglmayr \& Setchell, 1967; Pursel \& Graham, 1967; Neill \& Masters, 1972, 1973; Johnson, Pursel \& Gerrits, 1972; Poulos \& White, 1973; Poulos, Darin-Bennett \& White, 1973; Darin-Bennett, Poulos \& White, 1973b). These data led Poulos, Darin-Bennett \& White (1973) to suggest that the spermatozoa of these species could be allocated to two groups on the basis of the ratio of the phospholipid-bound polyunsaturated:saturated fatty acids, which could be correlated with sensitivity to cold-shock. Thus, the ratio for the spermatozoa of ram, bull and boar, which are known to be very susceptible to cold-shock, is approximately three times the ratio found for the less sensitive spermatozoa of the rabbit and human (Darin-Bennett $e t$ al., 1973a). In view of this apparent correlation, it was decided to examine the phospholipids of the spermatozoa of two other species, the dog and the fowl, which are relatively resistant to cold-shock (Wales \& White, 1959), and to determine whether the spermatozoa of these species can also be grouped according to their phospholipid-bound fatty acid and aldehyde content.

Semen was collected by massage and analyses were undertaken on pooled specimens containing a minimum of three ejaculates. Spermatozoa were separated and lipids were extracted as described by Poulos, Darin-Bennett \& White (1973). Two-dimensional thin layer chromatographic estimations of phospholipid composition were performed according to the methods of DarinBennett et al. (1973b). The phospholipid-bound fatty acid esters and dimethylacetals were prepared and estimated by gas-liquid chromatography (Poulos, Darin-Bennett \& White, 1973).

The percentage composition of the phospholipids and phospholipid-bound fatty acids and aldehydes of the dog and fowl spermatozoa are shown in Tables 1,2 and 3. The dog spermatozoa contained large amounts of phosphatidyl choline, phosphatidyl ethanolamine, sphingomyelin and ethanolamine plasmalogen and only small amounts of choline plasmalogen (Table 1). Fowl spermatozoa appeared to be different. Although phosphatidyl choline was the major component and the level of choline plasmalogen was quite low, there was no

* Present address: Department of Biochemistry, Adelaide Childrens Hospital, King William Road, North Adelaide, S.A. 5006, Australia. 
Table 1. The phospholipids of dog and fowl spermatozoa

\begin{tabular}{|c|c|c|}
\hline Lipid zone & Dog & Fowl \\
\hline $\begin{array}{l}\text { Total phospholipid phosphorus } \\
\text { ( } \mu \text { g atoms } / 10^{9} \text { sperm.) }\end{array}$ & $1 \cdot 88 \pm 0 \cdot 1$ & $2.33 \pm 0 \cdot 8$ \\
\hline $\begin{array}{l}\text { Phospholipids } \\
\text { (\%of total lipid phosphorus) } \\
\text { Origin } \\
\text { Lysolecithin } \\
\text { Sphingomyelin } \\
\text { Phosphatidyl serine } \\
\text { Phosphatidyl inositol } \\
\text { Choline plasmalogen } \\
\text { Phosphatidyl choline* } \\
\text { Ethanolamine plasmalogen } \\
\text { Phosphatidyl ethanolamine* } \\
\text { Cardiolipin } \\
\text { Miscellaneous lipids }\end{array}$ & $\begin{array}{r}3 \cdot 1 \pm 1.5 \\
0.2 \pm 0.1 \\
18 \cdot 3 \pm 2 \cdot 0 \\
3.6 \pm 0.3 \\
2.7 \pm 0.3 \\
3 \cdot 6 \pm 0.5 \\
27.5 \pm 1 \cdot 0 \\
15 \cdot 3 \pm 0.9 \\
20 \cdot 1 \pm 0.9 \\
3.0 \pm 0.3 \\
6.6\end{array}$ & $\begin{array}{r}1.7 \pm 0.8 \\
0.0 \pm 0.0 \\
13.1 \pm 0.6 \\
8.9 \pm 1.1 \\
1.6 \pm 0.3 \\
7.8 \pm 1.8 \\
39.6 \pm 0.7 \\
5.2 \pm 1.3 \\
8.5 \pm 0.5 \\
1.7 \pm 0.3 \\
10.7\end{array}$ \\
\hline
\end{tabular}

Each value is the mean \pm S.E. of four experiments.

* These fractions may have contained the corresponding alkyl ether phospholipid.

significant corresponding increase in proportion of ethanolamine phosphoglycerides; there was, however, an unusually large amount of phosphatidyl serine. These results for the fowl are in good agreement with the values found by Lake (1966) for sphingomyelin, ethanolamine and choline phosphoglyceride.

Palmitic (16:0) and docosapentaenoic (22:5) acids were the major phospholipid-bound fatty acids in dog spermatozoa but large amounts of stearic (18:0) and oleic (18:1) acids, and appreciable levels of arachidonic acid (20:4) were also present (Table 2). The phospholipids of fowl spermatozoa were mainly $18: 0$ and 18:1, rather than $16: 0$, and docosatetraenoic (22:4) acid was the major unsaturated acid. A considerable quantity of $16: 0$ and an unusually high level of $20: 4$ were present; $22: 5$ and $22: 6$, the principal unsaturated fatty acids of mammalian spermatozoa, were found in only minor amounts. In both species, the polyunsaturated:saturated fatty acid ratios of the sperm phospholipids were low (approximately 1.0).

The compositions of phospholipid-bound aldehydes were similar (Table 3); the major aldehydes were 16:0,18:0 and 18:1. The sperm phospholipids of fowl also contained an unusually large level of a substance tentatively identified as a 15:0 aldehyde, although the concentration of this compound in the aldehydes prepared by the method of Anderson, Garrett, Blank \& Snyder (1969) was slightly less than $15 \%$.

These results support earlier suggestions (Poulos, Darin-Bennett \& White, 1973; Darin-Bennett $e t$ al., 1973a) that the ratio of polyunsaturated:saturated phospholipid fatty acids can be linked to the susceptibility of spermatozoa to cold-shock, particularly as this has now been shown to apply to an avian as well as six mammalian species (Poulos, Darin-Bennett \& White, 1973). Additional support is given to the theory by the finding that this ratio in the testicular spermatozoa of bull and ram is 0.9 and 1.0 , respectively (Poulos, Voglmayr \& White, 1973; A. Poulos, P. D. C. Brown-Woodman, I. G. White, R. I. Cox \& R. F. Seamark, unpublished observation), and that testicular spermatozoa are 
Table 2. Phospholipid-bound fatty acids of dog and fowl spermatozoa

\begin{tabular}{|c|c|c|}
\hline $\begin{array}{l}\text { Fatty acid } \\
\text { (chain length: number of double } \\
\text { bonds) }\end{array}$ & $\begin{array}{l}\text { Dog } \\
(5)\end{array}$ & $\begin{array}{l}\text { Fowl } \\
(4)\end{array}$ \\
\hline $\begin{array}{c}14: 0 \\
16: 0 \\
18: 0 \\
18: 1 \\
18: 2 \\
18: 3 \\
20: 0 \\
20: 4^{*} \\
22: 3 \\
22: 4 \\
22: 5 \\
22: 6 \\
\text { Miscellaneous fatty acid }\end{array}$ & $\begin{array}{c}1.0 \pm 0 \cdot 6 \\
27.2 \pm 0.7 \\
13 \cdot 2 \pm 1 \cdot 4 \\
11 \cdot 8 \pm 0.9 \\
3.2 \pm 0.3 \\
1 \cdot 3 \pm 0.3 \\
\text { N.D. } \\
6 \cdot 6 \pm 0.7 \\
\text { N.D. } \\
\text { N.D. } \\
28 \cdot 4 \pm 3 \cdot 0 \\
3.9 \pm 1 \cdot 8 \\
0.5 \dagger\end{array}$ & $\begin{array}{l}\text { N.D. } \\
13 \cdot 6 \pm 0.9 \\
20 \cdot 3 \pm 1 \cdot 1 \\
19 \cdot 2 \pm 0 \cdot 7 \\
1.6 \pm 0.3 \\
\text { N.D. } \\
2 \cdot 9 \pm 0 \cdot 1 \\
10.2 \pm 1 \cdot 8 \\
3.8 \pm 0 \cdot 4 \\
24 \cdot 6 \pm 2 \cdot 6 \\
\text { N.D. } \\
2 \cdot 3 \pm 1 \cdot 1 \\
0.3 \pm\end{array}$ \\
\hline $\begin{array}{l}\text { Ratio of polyunsaturated: } \\
\text { saturated fatty acids } \oint\end{array}$ & 1.0 & $1 \cdot 1$ \\
\hline
\end{tabular}

The composition of each fatty acid is expressed as a percentage of the total weight. Mean values \pm S.E.M. are given for the replicates, and the number of replicates is shown in parentheses.

N.D. indicates that the fatty acid either was not detected or was present in amounts below $1 \%$.

* This fraction may also have contained 20:3.

$\dagger$ Fatty acids identified in this fraction include 15:0, 16:1, $17: 0,20: 0,20: 2$ and $22: 4$.

† Fatty acids identified in this fraction include 14:0, 15:0, $16: 1$ and $18: 3$.

is The polyunsaturated fatty acids are defined as those acids containing more than one double bond.

Table 3. Phospholipid-bound aldehydes of dog and fowl spermatozoa

\begin{tabular}{|c|c|c|}
\hline $\begin{array}{c}\text { Aldehyde } \\
\text { (chain length: number of double } \\
\text { bonds) }\end{array}$ & $\begin{array}{l}\text { Dog } \\
\text { (4) }\end{array}$ & $\begin{array}{c}\text { Fowl } \\
(3)\end{array}$ \\
\hline $\begin{array}{c}14: 0 \\
15: 0 \\
16: 0 \\
16: 1 \\
17: 0 \\
18: 0 \\
18: 1 \\
18: 2 \\
20: 0 \\
\text { Miscellaneous aldehydes }\end{array}$ & $\begin{array}{r}3 \cdot 3 \pm 1 \cdot 5 \\
5 \cdot 3 \pm 3 \cdot 5 \\
46 \cdot 5 \pm 5 \cdot 0 \\
4 \cdot 4 \pm 1 \cdot 4 \\
\mathrm{~N} . \bar{D} . \\
17 \cdot 2 \pm 1 \cdot 4 \\
15 \cdot 3 \pm 2 \cdot 9 \\
3 \cdot 0 \pm 1 \cdot 6 \\
1 \cdot 7 \pm 0.8 \\
1 \cdot 1 *\end{array}$ & $\begin{array}{l}2 \cdot 1 \pm 1 \cdot 1 \\
15 \cdot 0 \pm 2 \cdot 8 \\
53 \cdot 1 \pm 2 \cdot 8 \\
\text { N.D. } \\
3 \cdot 5 \pm 1 \cdot 6 \\
15 \cdot 7 \pm 2 \cdot 2 \\
10 \cdot 2 \pm 2 \cdot 2 \\
\text { N.D. } \\
\text { N.D. } \\
\text { 0.8† }\end{array}$ \\
\hline
\end{tabular}

The composition of each aldehyde is expressed as a percentage of the total peak area. Mean values \pm S.E.M. are given, while the number of replicates is shown in parentheses.

N.D. indicates that the aldehyde either was not detected or was present in amounts below $1 \%$.

* Aldehydes tentatively identified in this fraction include 15:0br, 17:0 and 18:3.

$\dagger$ Aldehydes tentatively identified in this fraction include $15: 0 \mathrm{br}, 16: 1$ and $18: 2$. 
far more resistant to cold-shock than are the corresponding ejaculated spermatozoa (Quinn \& White, 1967) for which the ratios are 3.0 for bull and 2.5 for ram (Poulos, Darin-Bennett \& White, 1973; Neill \& Masters, 1972, 1973).

The authors are indebted to Professor C. W. Emmens for his interest and advice. We should also like to thank Tegels, Camden, N.S.W., for providing the fowl semen. The work has been aided by grants from the Australian Research Grants Committee and the Ford Foundation. One of the authors (A.P.) was the recipient of a Sydney University Post-Doctoral Fellowship.

\section{REFERENGES}

Anderson, R. E., Garrett, R. D., Blank, M. F. \& Snyder, F. (1969) The quantitative production of aldehydes from 1-o-alk-1-enyl glycerols. Lipids, 4, 327.

Darin-Bennetr, A., Poulos, A. \& White, I. G. (1973a) The fatty acids and aldehydes of spermatozoan phospholipids. Proc. Aust. biochem. Soc. 6, 29.

Darin-Bennett, A., Poulos, A. \& White, I. G. (1973b) The effect of cold-shock and freeze-thawing on the release of phospholipids by ram, bull and boar spermatozoa. Aust. F. biol. Sci. 26, 1409.

Johnson, L. A., Pursel, V. G. \& Gerrits, R. J. (1972) Total phospholipid and phospholipid fatty acid composition of ejaculated and epididymal semen and seminal vesicle fluid of boars. J. Anim. Sci. 35, 398.

Lake, P. E. (1966) Physiology and biochemistry of poultry semen. Adv. Reprod. Physiol. 1, 93.

Neils, A. R. \& Masters, G. J. (1972) Metabolism of fatty acids by bovine spermatozoa. Biochem. $\mathcal{F}$. $127,375$.

Neill, A. R. \& Masters, G. J. (1973) Metabolism of fatty acids by ovine spermatozoa. F. Reprod. Fert. 34, 279.

Poulos, A., Darin-BennetT, A. \& White, I. G. (1973) The phospholipid-bound fatty acids and aldehydes of mammalian spermatozoa. Comp. Biochem. Physiol. 46, 541.

Poulos, A., Voglmayr, J. K. \& Whrte, I. G. (1973) Phospholipid changes in spermatozoa during passage through the genital tract of the bull. Biochim. biophys. Acta, 306, 194.

Poulos, A. \& WhIte, I. G. (1973) The phospholipids of human spermatozoa and seminal plasma. 7. Reprod. Fert. 35, 265.

Pursel, V. G. \& Graham, E. F. (1967) Phospholipids of bovine spermatozoa and seminal plasma. 7. Reprod. Fert. 14, 203.

Quinn, P. J. \& White, I. G. (1967) Phospholipid and cholesterol content of epididymal and ejaculated ram spermatozoa and seminal plasma in relation to cold-shock. Aust. F. biol. Sci. 20, 1205.

Scott, T. W., Voglmayr, J. K. \& Setchell, B. P. (1967) Lipid composition and metabolism in testicular and ejaculated ram spermatozoa. Biochem. $\mathcal{F} .102,456$.

WALES, R. G. \& WhITE, I. G. (1959) The susceptibility of spermatozoa to temperature shock. $\mathcal{F}$. Endocr. 19, 211. 